\title{
Review of Available SW Solutions for Intellectual Property Management Systems from the Perspective of Open Innovation
}

\author{
Ondrej Krejcar $^{1, *(\mathbb{D})}$, Robert Frischer ${ }^{1}$, Robert Hlavica ${ }^{1}$, Kamil Kuca ${ }^{1} \mathbb{D}$, Petra Maresova ${ }^{2}(\mathbb{D})$ and \\ Ali Selamat $1,3,4$ (D) \\ 1 Center for Basic and Applied Research, Faculty of Informatics and Management, University of Hradec \\ Kralove, Rokitanskeho 62, 50003 Hradec Kralove, Czech Republic; Robert.frischer@uhk.cz (R.F.); \\ r.hlavica@gmail.com (R.H.); kamil.kuca@uhk.cz (K.K.); aselamat@utm.my (A.S.) \\ 2 Department of Economy, Faculty of Informatics and Management, University of Hradec Kralove, \\ Rokitanskeho 62/26, 50003 Hradec Kralove, Czech Republic; petra.maresova@uhk.cz \\ 3 Malaysia-Japan International Institute of Technology, Universiti Teknologi Malaysia Kuala Lumpur, \\ Jalan Sultan Yahya Petra, Kuala Lumpur 54100, Malaysia \\ 4 Media and Games Center of Excellence (MagicX), Universiti Teknologi Malaysia, Skudai, Johor Bahru, \\ Johor 81310, Malaysia \\ * Correspondence: ondrej.krejcar@uhk.cz
}

Received: 29 February 2020; Accepted: 25 March 2020; Published: 30 March 2020

\begin{abstract}
This piece of research is focused on providing a review of the software solutions that exist when it comes to mechanisms that govern the management of intellectual property. It takes a deeper look at requirements within the university transfer office domain. Universities are a genuine source of knowledge. They have been identified not just as knowledge hubs but also as the spaces where innovations are born. These innovations then make their way into the market through the different industries they serve, becoming products that gain the attention of actual consumers. Given the magnitude of the innovations being developed in different universities around the world, it is imperative that mechanisms for the safety of this knowledge also be put into place. The world has evolved into a knowledge economy, where knowledge is an asset and something that can create profitability. This means that not protecting the knowledge that is being created can only lead to a loss in the future. Managing intellectual property, therefore, is not only a matter of procedure but one of great importance. Solutions that are easily accessible, cost-effective, and time-effective are essential. Thus, the goal of this article is to provide an overview of existing software (SW) solutions suitable for managing technology and knowledge transfer at universities based on requirements from the technology transfer office at university and specified using the model of the whole process from inventor until patent office. University Technology Transfer (TT) is a bit different in comparison to TT at companies. This gap is shown in the article using modelling of process, states, and class diagrams of a university Technology Transfer Office (TTO). Based on process definition and TTO responsibilities, a review of available SW solutions is done for 10 selected examples, as well as a related literature analysis. Findings and implications are summarized at the end of article in the context of specific needs of a university TTO, while major implications are shown as a problem of priority definition of every university TTO, namely, in the sense of value of SW solutions for intellectual property (IP) management, reporting possibilities, and representing IP and know-how.
\end{abstract}

Keywords: technology transfer; knowledge; intellectual property; open innovation; patent; software; management 


\section{Introduction}

Countries that have decided to promote science, research, and innovation as key national priorities are among the most prosperous today. Managing intellectual property poses its own challenges and difficulties. As the world moves towards digital solutions for most problems, the field of intellectual property management systems (IPMS) has also evolved. The main motivation behind any research and development activity that takes place at the domestic and international level is to create more data and help aid the development of economies. This can be accomplished through engagement or collaboration between the business world and academia. To promote such cooperation, technology transfer centers are being developed. In the Czech Republic, such centers were developed with the aid of funds from the EU, Operational Program of OP RaDI, and the 3 Priority Axis 3.3 Challenge, during the previous programming period. Another challenge is the further development of these centers, as experience from abroad shows the need for these centers on one hand and the issue of their future funding on the other hand.

One of the questions and challenges that research centers are addressing as a result of greater pressure to ensure proper operation with less financial support is the question of software that provides the process of intellectual property protection management. Thus far, the possibility of financing even high-cost SW has ended, and it is necessary to provide a cheaper option if they are not sufficiently profitable. This paper presents a substantial review of the many software solutions that exist for this very purpose. There are several examples of journal articles published in recent years with the goal of defining technology transfer at the university level, specific country issues, searching for some SW solutions, and more. This scientific background, which is focused on technology transfer processes at universities, managerial aspects in relation to different types of economics, legislative conditions, and different levels of cooperation with practice are important inputs for effective managerial tools for technology transfer processes. Arenas and Gonzalez [1] looked at technology transfer models and elements in collaborations that involve universities and industries. Universities, the authors note, are centers of knowledge and lead to the creation of innovative products. The study looked at a review of tech transfers that had happened during such collaborations. It discussed 66 papers in total to expand on this model. Our team also added some points to this discussion by Maresova, Stemberkova, and Fadeyi [2], where we conducted similar research into the models, processes, and roles that universities play when it comes to the management of technology transfers. It discussed investing, marketing, internal strategizing, and academic entrepreneurship and policies. Universities act as mediators between innovation and the industry, in a manner of speaking.

$\mathrm{Li}$, Zhang, and Jin [3] also discuss the sustainability of the transfers in question. The study created a model that takes into account the inventor's technology service through the lens of a long-term link to a company. It looks at the mediating impact that this has on the technology transfer sustainability of the university. The survey-based study concluded that having such a service in place has a considerably advantageous impact on the practice tendency and attitude tendency of the company's longer-term technology leanings. The study also noted that the technological absorption capacity between a university and company has a serious impact on the inventor's technical service availability. Choi, Jang, Jun, et al. [4] looked at a predictive model for technology transfers through the use of a patent analysis system. The study noted that it has not been possible for most to keep up with the evolution of technology. In order for research and development practitioners to be able to carry out their jobs successfully, it is imperative that some form of patent information analysis is executed. Technology commercialization is heavily linked to the transfer of tech itself. The authors proposed a predictive model, which can be helpful in predicting said transfers, and ensuring that a mismatch error does not occur in terms of expert opinions. This will help reduce or curb the waste of resources when it comes to research and development. This model has been built by pre-processing patent data and executing a social network analysis, alongside decision tree modelling, and a linear regression analysis.

Innovation is a key concept in the whole context of technology transfer. Innovations are defined in different ways in literature. Chen, Zhao, and Wang [5] expand on the concept by calling it the entrance 
of a new set of important elements that inform the production process or influence the production system. Innovation capital has several components, not only human capital, but also organizational and relational. The benefit of this component lies in the fact that, after the established links, the intentions of the organization's social mission are disseminated and the relationship to the key values determining the orientation of its innovation strategy is strengthened. The specification of innovation capital is "the use of purposive inflows and outflows of knowledge to accelerate internal innovation, and to expand the markets for external use of innovation" [6]. Open innovation is a cross-sectoral approach, so the whole issue will be discussed in the context of this aspect.

From the arguments discussed above, we can see that control over the process of knowledge transfer is crucial for the application of research and development results. The question of appropriate SW solutions as a supporting tool for this process will be discussed. The approach of the selected country i.e., the Czech Republic, which is one of the countries to have built R\&D centers and has worked independently in connection with existing support, the criterion for software solutions can be evaluated, alongside the context and funding opportunities.

The relevant theoretical framework is discussed in Section 2. The methodology of the approach is dealt with in Section 3, while the semi-structured face-to-face interviews are specified in Section 3.2 of this article. After this, the definition of requirements for SW solution discussions and implications of findings are summarized in Section 4 findings, while the summary of fulfilment of declared university technology transfer office requirements are discussed in brief in Section 5.

\section{Theoretical Framework}

\subsection{TTOs in Research Universities}

TTOs' primary goal is to help research output reach its potential commercially. The development of new companies and licensing of intellectual content are typically seen as the main paths through which university research is commercialized [7]. Siegel and Wright [8] point out that TTO-related literature typically looks at licensing and patenting, whereas spin-offs are becoming more and more understood to be significant avenues through which commercialization can be achieved. Although TTOs have a significant part to play within this process, studies done in the past note that other parts of the universities involved can play complementary roles to help. For instance, Calder and Debande [9] noted that a university with a science park and TTO will have a better performance because of the intertwined nature of the work. Another study by Squicciarini [10] demonstrated that science park tenants have a higher likelihood of getting a patent. On the other hand, Wright, Liu, Buck, et al. [11] have outlined that complementary assets are needed by entrepreneurs when they consider relocation to a science park. When we do a quick comparison, we see that incubators do not play such large a role when it comes to the transfer of technology, at least in the past. Markman, Phan, Balkin, et al. [12] noted that they are not associated with TTO or the strategy for transfer of technology. Seigel and Phan [13] noted similar results in their study, where they reported that incubators have to play a supporting role when it comes to the research being undertaken by scientists at universities, at the point where patenting is being done. To be commercially successful, TTOs must acquire, monitor, and protect new innovations and inventions. Furthermore, they must also create links in the industry and be conscious of the fact that several problems impacting these innovations will present themselves. This will allow inventors to make use of this relevant resource to help provide the knowledge and networks for the given industries and fields. Many papers look at the TTO process, which typically starts with reviewing (non-public) invention disclosures that are made at the TTOs by university researchers [14]. An important decision is then whether or not to patent the disclosed invention. The support infrastructure, previous experience of patenting, and support from the public transfer infrastructure also have a positive impact. It is further argued that all incentive systems in both countries are based on publications and it is therefore suggested that there should be incentives also for patenting as part of the third mission. 


\subsection{Intellectual Property Management System}

According to Schoen, van Pottelsberghe de la Potterie, and Henkel [15], the TTO process typically includes "disclosing inventions, conducting early economic assessment, deciding if the invention should be patented, filing the patent, searching for licensees, negotiating the contract conditions (with industry partner or spin-out companies), and monitoring royalties" [15]. By identifying four different types of TTOs (the classical, the autonomous, the discipline-integrated, and the discipline-specialized), the authors are able to show that comparisons between universities with different goals and different governance models for technology transfer may be misleading. A similar description of the general TTO process has been produced by Kamariah [16], who described how the commercialization of patents is dealt with in seven different UK universities. They also point at the choice between commercialization through licensing and spin-offs.

The IPMS is a tool that covers management and policy and helps accumulate and enhance the values associated with a good intellectual property (IP) portfolio. Strategy implementation, when it comes to IP, necessitates contribution from different organizational subsystems. As a result, this helps maintain the framework alongside the portfolio. Moreover, this process includes the maintenance of the patent portfolio, including augmenting the flow of possible patents for the decision process itself, valuation, cost management, and determination of the optimal parameters for conversion so as to extract value from the patent.

An IPMS has five main aspects when it comes to responsibility, including the creation of intellectual property, portfolio management, valuation, decision making, and competitive evaluation.

An IPMS helps maintain the entire inventory of IPs at the company's disposal. It also evaluates the value of the assets owned. It furthermore highlights how the IP should be taken as a legal document, as a tool for decision making at both the business and strategic level, and as a business asset.

The above processes are related to the management of intellectual property protection and are crucial for the correct setting of the TT management system.

Liu and Chin [17] have an interesting solution to tackling the intellectual property management question. They created an audit system for the purpose of managing IPs. Innovation cannot flourish without robust systems to manage intellectual property. Under the system proposed by the authors, the process of managing IPs is broken down into a list of enabling criteria, which can then be measured. These are essentially the success factors that help ensure that a decent management practice is set in place. An analytic hierarchy process approach was implemented to find the relative significance in terms of the criteria outlined under the audit system. This allows organizations to find the chinks in the armor of their IP management practices and allows for their strengths to be highlighted as well.

\section{Methodology}

The study design is based on three main steps. The first step is to analyze and compare the available literature relating to technology transfer processes [18].

\subsection{Literature Review}

The searching strategy was restricted only for records within a time range between years 2009 up to 2019, covering both journal articles (including reviews) and conference proceedings. As a data source, the ISI WOK database was used. The exact string was ("Management System" OR "software" OR "framework") AND ("Intellectual Property") in "title" only. Selected ISI WOK indexes covered: SCI-EXPANDED, SSCI, A\&HCI, CPCI-S, CPCI-SSH, BKCI-S, BKCI-SSH, ESCI, CCR-EXPANDED, IC.

Searching resulted in 74 records from 45 Web of Science categories, such as LAW (28), BUSINESS (11), MANAGEMENT (10), COMPUTER SCIENCE INFORMATION SYSTEMS (9), INFORMATION SCIENCE LIBRARY SCIENCE (9), and others.

These records were analyzed mainly to see their eligibility and relevancy as an SW solution for intellectual property management. 
Finally, after full text reading, only 11 records were included in the review, where $3 x$ conference proceedings and $8 x$ journal articles were fully analyzed. Decomposition of records was equal in years, as in years 2009, 2010, 2011, 2012, 2015, 2018, and 2019 only one record was selected, and in 2016 and 2017 two records were used.

The journal "World Patent Information" from the Emerging Sources Citation Index was the most frequently used as an information source. Other journals cover also the first quartile (Q1) impact factor (IF) journals according to the Journal Citation Report (JCR) from ISI WOK, such as "Engineering Applications of Artificial Intelligence" and "Expert Systems with Applications", both from Computer Science and Engineering ISI WOK categories. These two journal articles have also received 9 and 10 citations already, which proves the high importance of this research for the research community.

\subsection{Interview}

The second step is the semi-structured face-to-face interviews, which were conducted with the TTO head of four universities within the Czech Republic. The interview questionnaire was created keeping in mind intervention logic and its principles [19]. It consisted of 12 main questions for evaluation. The collection of interviews ran between February to September 2019. Four interviews were completed during this time, and the respondents answered the questions posed willingly in most cases. The comments were supported with information and facts. The approved concept of evaluation was implemented to interpret the interview results. The respondents' answers were used within the analysis and split into three main themes.

The first block looks at the processes in terms of how they were being developed and registered. It also delved into whether the university had a methodology in place, and who had access to the processes in question. We also looked at how these processes were divided, their level of completion, and the particle actions that were linked to the costs, and the extent to which this was relevant.

Evaluation of the efficiency of the process-questions focused on variant models and target groups according to the research area and requirements for the proposed SW and, finally, related costs.

\subsection{Review of Available SW Solutions}

Based on the summarized parameters, the next step lay in the review of all available SW solutions for IP management according to selected parameters. There are several existing specialized websites, which are focused on offering these SW solutions; searching for these SW solutions according to the selected parameters (filtering) and also providing feedback from customers in the sense of full written reviews or the level of valued like/dislike evaluation in several parameters. Since the goal of this article is to provide a review of available SW solutions, we selected not only the SW solutions that fully fulfilled all selected parameters from interviews, but also several others, thus the final count of reviewed SW solutions is ten.

As the needs of company TTO and especially university TTO varies by countries, different law systems or different university forms/decrees, as summarized in Table 1, allow the strengthening of the most important parameters for specific TTOs and to easily narrow the number of SW solutions which need to be fully analyzed by TTOs, or which need to be contacted for price options or other aspects of specific TTOs. Later in Section 4.3, the use of the case of the Czech Republic is given as an example of specific needs of TTOs and fulfilment of important parameters for specific national cases. 
Table 1. Selected SW solutions for managing intellectual properties with main features.

\begin{tabular}{|c|c|c|c|c|c|c|c|c|c|c|c|}
\hline & Developer & TM Cloud & $\begin{array}{l}\text { Inteum } \\
\text { Company }\end{array}$ & $\begin{array}{c}\text { Harbor } \\
\text { Technologies }\end{array}$ & $\begin{array}{c}\text { About } \\
\text { Innovation }\end{array}$ & CPA Global & GMV & $\begin{array}{c}\text { MaxVal } \\
\text { Group }\end{array}$ & Anaqua & $\begin{array}{c}\text { Thomson IP } \\
\text { Manager }\end{array}$ & $\begin{array}{c}\text { Derwent } \\
\text { Innovation }\end{array}$ \\
\hline & SW Name & TM Cloud & Inteum & $\begin{array}{c}\text { IPzen } \\
\text { Professional }\end{array}$ & $\begin{array}{c}\text { About } \\
\text { Innovation }\end{array}$ & FoundationIP & IDEAS & Symphony & Acclaim IP & $\begin{array}{c}\text { Thomson IP } \\
\text { Manager }\end{array}$ & $\begin{array}{c}\text { Derwent } \\
\text { Innovation }\end{array}$ \\
\hline & $\begin{array}{l}\text { Starting Price } \\
\text { [USD/month] }\end{array}$ & 100 & - & - & 229 & - & - & - & - & - & - \\
\hline \multirow{10}{*}{$\begin{array}{l}\text { Product } \\
\text { Features }\end{array}$} & $\begin{array}{c}\text { Information } \\
\text { Disclosure } \\
\text { Management }\end{array}$ & - & $x$ & $x$ & $x$ & $x$ & $x$ & $x$ & $x$ & $x$ & $x$ \\
\hline & $\begin{array}{c}\text { IP Portfolio } \\
\text { Management }\end{array}$ & $x$ & $x$ & $x$ & $x$ & $x$ & $x$ & $x$ & $x$ & $x$ & $x$ \\
\hline & $\begin{array}{l}\text { Trademark } \\
\text { Tracking }\end{array}$ & $x$ & $x$ & $x$ & $x$ & $x$ & $x$ & - & - & $x$ & $x$ \\
\hline & $\begin{array}{c}\text { Deadline } \\
\text { Management }\end{array}$ & $x$ & $x$ & $x$ & $x$ & $x$ & $x$ & $x$ & - & $x$ & $x$ \\
\hline & $\begin{array}{c}\text { Docket } \\
\text { Management }\end{array}$ & $x$ & $x$ & $x$ & - & $x$ & $x$ & $x$ & - & $x$ & $x$ \\
\hline & $\begin{array}{c}\text { Document } \\
\text { Management }\end{array}$ & $x$ & $x$ & $x$ & $x$ & $x$ & $x$ & $X$ & $x$ & $x$ & $x$ \\
\hline & Patent Tracking & $x$ & $x$ & $x$ & $x$ & $x$ & $x$ & $x$ & $x$ & $x$ & $x$ \\
\hline & $\begin{array}{c}\text { Renewal } \\
\text { Management }\end{array}$ & $x$ & $x$ & $x$ & $x$ & $x$ & $x$ & $x$ & $x$ & $x$ & $x$ \\
\hline & $\begin{array}{c}\text { Spend } \\
\text { Management }\end{array}$ & - & $x$ & $x$ & $x$ & $x$ & $x$ & $x$ & $x$ & $x$ & $x$ \\
\hline & Users & $100-499$ & 1-1000+ & 1-1000+ & 1-1000+ & 1-1000+ & 1-1000+ & 2-1000+ & 1-1000+ & $1000+$ & $-1000+$ \\
\hline \multirow{4}{*}{ Deployment } & Web-Based & $x$ & $x$ & $x$ & $x$ & $x$ & $x$ & $x$ & $x$ & $x$ & $x$ \\
\hline & Installed & $x$ & $x$ & - & - & - & - & - & - & - & - \\
\hline & iOS & - & - & - & - & - & - & - & - & - & - \\
\hline & Android & - & - & - & - & - & - & - & - & - & - \\
\hline
\end{tabular}


Section 4's findings deal with a deeper analysis of data and process flow in the university TTO supported by the class model and process diagrams.

\section{Findings}

\subsection{SW Analysis and Literature Review}

\subsubsection{Literature Review}

There are a number of studies and journal articles dealing with some form of developed SW solutions for technology or knowledge transfer from which we selected the most interesting ones to be described in more detail in the following text.

Porrawatpreyakorn [20] presented a study on executive information systems (EIS) within the Thai telecommunications sector. The study noted the requirements that are necessitated by virtue of knowledge transfer (KT) frameworks. This approach includes two main facets; the proposed software development lifecycle and the proposed KT framework itself. The main aim of this study was to develop a management setup that could augment efficacy. EIS have helped several countries induct more IT-based solutions into their workings. Such systems allow for better communication, control, planning, and coordination, allowing for a more time and cost-effective solution.

Similarly, Barac, Kukolj, Antin, et al. [21] looked at software support in terms of processes that involve managing intellectual property. The discussion is put forward through the lens of a Small Medium Enterprises (SME) company focused on digital entertainment. The software support in question covered the management of patents and included elements such as client-server architecture. The system works by connecting the client and the server through the given architecture. It allows for the interface to create a solution that works through the internet and provides support for the patenting process itself.

Gargate and Momaya [22] created an IPM model that could be used to create and analyze the system being created. The study looked at the gaps that organizations at times have to work with, specifically when it comes to developing countries that may not enjoy the same smooth legal proceedings as developed countries. The gap between the generation of intellectual property and its commercialization need to be reduced, if not removed. This guidance points out that a system that is developed must be created keeping its end-users and environment-related realities in mind. The IPM model therefore helps create a solution that is locally relevant. It outlines five main stages and 15 IPM processes that a developer must keep in mind.

Tsybulskaia, Ryabtseva, Strashko, et al. [23] note that planning, organization, and motivation of management entities helps commercialization of intellectual property (IP). The management is the one that will create ideas and innovation, and then execute them, and later control and regulate how these ideas are used. The study discussed different approaches to this commercialization. The study notes that for an effective approach, the economic, social, technical, and informational aspect of the IP in question must be taken into account. The final system must take into account the needs and requirements of both the producer of the IP and the consumer of the same.

Charavay, Segard, Pochon, et al. [24] developed a software program that could help augment the management of seed stock and plant line exchanges. The software had a component that was focused on protecting intellectual property. The program itself has been developed in a way that it corresponds to the needs of the person using it. Any laboratory looking for innovation outlooks on lab management can use the system.

A university system to manage intellectual property was developed by $\mathrm{Yu}$ [25]. The study notes that the world is moving rapidly ahead in a knowledge-based society, where all our actions are informed by our knowledge-driven economies. In such a scenario, the significance of creating systems to protect said knowledge cannot be undersold. Universities are the cornerstone of knowledge development, however, a lack of IPM can be observed in most places. The study puts forward a design 
for an IPMS that could help fortify knowledge being produced in universities. An intelligent system that can understand the needs of the knowledge economy is the need of the hour.

A similar approach was undertaken by Kadir and Salim [26] who looked at a management and monitoring system for IP rights that were related to the university innovation center. This study confirms that as the knowledge economy grows, knowledge becomes an important economic tool and asset. Educational institutions are understanding the need to safeguard the information, data, innovation, and ideas that they create. Growing competition also ensures that institutes are now invested in safekeeping their intellectual property so that they can retain or gain an edge. The system outlined in the study offers a guideline that allows for effective management, which is built as per the environment of the center it is meant for. This study also confirms the need to take into account the end-user and environment that the system will be used in.

Dirnberger [27] goes a step further by outlining mind mapping software that can help both manage and search for patents. The study notes that modern IT systems, and especially the internet, have made it possible to access a great amount of information with extreme ease and speed. Professionals can procure this information both from within a company's own resources and through external means. The digital mapping technique under discussion in this study helps tie together existing solutions so that managing and searching for patents can be optimized. This is done through organizing information sources with efficiency in mind. The system helps track content in a comprehensive yet succinct manner.

Tao, Zhang, and Zhou [28] looked at a case study from China to outline IP management. The study notes that ensuring that there is proper and strong management of intellectual property rights is an important aspect when it comes to augmenting an enterprise's capacity to innovate. It looks at the example of NineStar Technology Co., which operates out of China and has managed to develop a system to manage their IPs while they promote their products. They are better positioned to deal with foreign litigation relating to patents because of this. The six main elements that go into creating an effective system, such as that of NineStar, include an information system, an establishing system, an operations system, a protection system, a development system, and a strategic system.

Wang and Cheung [29] discuss an IPMS that is based on a semantic approach. Patent databases make it possible for a more refined version of technology management to exist. As the number of patents grow each year, they become harder to search for and analyze. There are many reasons for these difficulties, including the richness and length of the text and the complexities of the language used. The study puts forth that an automated system for patent analysis would prove useful to investors and innovators, which is where the semantics approach comes from. This is different from conventional methods because it uses the global patent databases already available as the pool from which information can be drawn, as opposed to relying on experts to do the job.

\subsubsection{Review of Available SW Solutions}

This section will take a look at available software solutions for IP management. It will discuss their working so that the most appropriate solutions can be found, and their strengths and weaknesses can be understood.

The first solution that this research will discuss is the TM Cloud [30]. Created in 2011 in the United States, the trademark docketing and intellectual property management solution allows access from anywhere in the world. It offers trademark data, United States Patent and Trademark Office (USPTO) [31] status updates, and has audits in around 175 jurisdictions. The tool makes it possible for a user to search for information in 100 jurisdictions. Some of the types of information one can find include domain names, searchers, copyrights, disputes, and patents [30]. The software is regularly used by law firms and legal departments that exist within companies when they are trying to address trademark, patent, and other similar issues. The application is not restricted to the United States-if anything, this is a tool that is used worldwide. The cloud-based software is both time and cost efficient for its users. This is one of the most widely used and popular solutions to exist. 
The second option is Inteum [32], which was developed in 1992. This management software essentially covers a range of innovations. It goes beyond managing just a trademark or a copyright and covers a lot more. It is an innovation management system in the truest sense. This is a web-based solution that allows for quick access when needed. Data can be assembled and managed easily, and reports can be generated from the same without a hitch. An interesting feature is the ability for businesses to ask for custom programming. This allows them to be able to have specific needs addressed, and confirms the ideas put forth by Gargate and Momaya [22] that a solution needs to make sense to the end-users who will be implementing it, i.e., it must be suited to the environment it is being created for. Inteum is, like TM Cloud [30], a widely used solution in the market.

IPzen Professional [33] has been created by lawyers and runs through a cloud platform. It has the ability to help them create invoices, manage cases, trademarks, and more. The France-based company was created in 2008 and has several key features that make it an excellent option when it comes to intellectual property management. Its simple interface allows for simple use that the user does not find distracting or disruptive. "The functional and business strength of the solution resides with its extensive and easy-to-do parameterization. In that, it enables matching simple to complex organizational company processes, involving a few to a great many contributors. The modular structure of the solution gives flexibility to tailor the functional scope to one's specific business needs. With time, should business needs evolve, a scale-up is entirely possible seamlessly".

About Innovation [34] is another tool that is frequently used by lawyers and is specifically designed to handle IP management. The company was developed in 2017 in France but has fast made its own space in the market. It allows users to manage documents, deadlines, IP portfolios, patent tracking, renewals, and more. The dedicated services are available through a software as a service (SaaS) model and can be easily used over the internet. This is a collaborative platform that allows organizations to easily replicate their workings so that their actual aims can be addressed as needed. The interface is extremely easy to use and comes with visual tools necessary to get the work done properly. IP data can be leveraged so that the portfolio and strategy is easily augmented for better results.

FoundationIP [35] has been developed by CPA Global, which is one of the oldest companies around. It is used by more than 600 firms around the world, making it an important solution. CPA Global itself was created in 1969 in the United Kingdom and has evolved over the years to include a web-based solution. FoundationIP [35] has been developed with the specific goal of allowing the people working on IP operations to be able to manage intellectual property better. It also deploys a SaaS platform that has the ability to help users bring costs down, tackle risks in an easier fashion, improve collaboration, and augment efficiency. The platform was created after research that included an insight into how law firms and legal departments function. Amongst the many solutions it offers, users can manage documents, dockets, deadlines, IP portfolios, and more. The solution is refreshed and updated in live time and covers multiple Patent and Trademark Office PTOs and jurisdictions.

Developed by GMV, IDEAS [36] is software that helps with IP management in the entirety of its life cycle. This means that it is able to help with the management at every step of the way. The product was created keeping inventors and innovators in mind-be it an individual or a company. It is flexible enough to be able to address different needs of the users that take it on to manage their IPs. GMV was created in Spain during 1984, which means that it has decades of experience behind it. Users can use this solution to manage deadlines, dockets, documents, portfolios, information disclosures, patents, renewals, and more. The software allows for customization and personalization so that specific needs can be addressed. It is easy to create a tailor-made solution through the many templates that the software already has.

The MaxVal Group's Symphony [37] software has been deployed by leading companies in the world, including pharmaceuticals, tech firms, medical device developers, and more. This is a cloud-based service that was deployed by the company in 2016 (although MaxVal Group itself was created in 2004). It allows for better workflows and provides access to global patent information. Users can manage dockets, deadlines, documents, portfolios, and more through the use of this service. The 
interface is easy to use and offers multiple methods of taking data to create reports and keep an eye on the information that matters.

Another piece of software is Anaqua [38]. This allows companies to gain a competitive advantage by helping to provide a modern solution to the intellectual property question. It augments innovation, allows for protection, and helps develop the insight that a company would need before they make their IP decisions. The software puts together several aspects of IPM by intertwining collaboration, workflow, data, docketing, and patient analyses. Anaqua is essentially a SaaS platform that allows for more fluid working. The company also has a team of IP experts on board to help create a process that can ensure that accurate data informs every decision made. For international clients, the software comes with localized help and support-Anaqua works out of six countries around the world.

Thomson IP Manager [39] revolves around helping a person or enterprise manage their IP portfolio. The software is clearly laid out and can be used remotely, giving it an edge for people who may have to travel while managing IPs. The service comes equipped with support in case users are confused or need more information about a feature. This is one of the pricier options in the market, which means that it cannot be as useful for individuals, especially those without any large funds behind them. The software also comes equipped with reporting tools which help save time and create reports in a cost-effective manner. Helpful features, such as the Global Change function, allow users to switch modes if they are working with a bigger company. The only shortfall is that this software can prove to be a little complicated for some users.

The last piece of software under discussion is the Derwent Innovation [40]. It has been created by Clarivate Analytics and serves more than 40,000 users. The clientele that this software works with consists of both people who are innovating and creating new things and legal professionals who are helping the creators manage their intellectual property. The software can help users assess patentability, support legal proceedings against patent infringement, help with monetization of patents, mitigate infringement risk, and help evaluate the competition. It helps users build a complete picture of whatever they are working on. Users can look at global patent data or go through the World Patents Index for more information. The software has a complete solution when it comes to harnessing the power of intellectual property. A summary of the most requested and standard features is in Table 1.

Several of these solutions offer similar tools or services, which is understandable given that they are geared towards similar outcomes. However, some solutions prove to be superior because of some features that are either better than the others or simply not present in the others. There are solutions that make more sense because they come from companies with decades of experience in understanding and handling business environments, and others that have understood how digital tools need to be shaped and molded to deal with the rapidly evolving needs of our times.

\subsubsection{Research Articles vs. Available IP Management SW Solutions}

Porrawatpreyakorn's [20] emphasis on software that takes into account the development cycle or lifecycle of the innovation immediately brings attention to IDEAS [36]. This is one piece of software that allows for IP management throughout the life cycle of the innovation in question. The most interesting ability that this software has is that it can be customized towards a specific intellectual property or patent, making it the most appropriate choice-this will help address cost-effective, localized needs.

IDEAS [36] also corresponds to Charavay, Segard, Pochon, et al. in 2017 [24], who worked on a program that could augment seed stock management, and plant line exchanges. The very important aspect here is that innovation in terms of lab management be managed in the manner that the user requires, which is the kind of flexibility that this software offers, too. With flexibility, software is able to actually not only address the requirements at hand but deliver results in the most appropriate manner.

Our review also noted Gargate and Momaya's [22] approach, which was focused on developing countries, where IPs are either not recognized or not managed properly because of lax or inadequate legal structures. Here, MaxVal Group's Symphony [37] may prove to be extremely useful because its easy-to-use interface connects users with global patent information. The other option that makes sense 
in connection to the authors' work is Inteum [32], which allows for specific needs to be addressed—much like IDEAS does.

Tsybulskaia, Ryabtseva, Strashko, et al. in 2019 [23] highlighted the commercial aspect of intellectual property. Tao, Zhang, and Zhou in 2012 [28] noted similar findings, albeit from the point of view of an enterprise. The one solution that hits the mark in terms of this study is Derwent Innovation [40]. It works with more than 40,000 users, which is a large sum. A core function of this software is to help their users figure out a way to monetize their patents, which is an extremely important aspect of the current knowledge economy. In addition, it can also help them find out whether an idea can be patented or if it would go into infringement territory. The fact that it can help users mitigate risks means that it can allow for better preparedness for the future.

Yu in 2017 [25] looked at the competitive edge that universities try to achieve through their intellectual property. The need for an intelligent system that could leverage IP was highlighted in this work. Similarly, Kadir and Salim in 2016 [41] reported that effective management of IP was needed for success. FoundationIP [35], developed by CPA Global, addresses the commercial aspects fairly well. The SaaS platform can help bring costs down, augment collaboration, and improve efficiency.

Anaqua [38] also helps keep profit and competition in mind. It allows innovations to not only find protection through legal measures but also helps its users develop insights that can help them make better IP decisions. This is another SaaS platform, which means that it allows for flexibility and better collaboration. Similarly, Thomson IP Manager makes it possible for companies to remotely find their competitive advantage. It can help a user switch between large and small firms with great ease, and also allows for excellent reporting. Anyone who is looking to understand a patient's potential would find this tool extremely useful.

IDEAS, Symphony, and FoundationIP all allow for mapping of information through their tools. Dirnberger in 2016 [27] noted that mind mapping software could help manage and search for patents. This level of optimization can be found in almost all the solutions that have been highlighted in the previous section.

Liu and Chin in 2010 [17] developed an audit system to look at intellectual property. This kind of an implementation can be done through FoundationIP as well, which allows users to perform a range of tasks so that they can understand their patents better. Their main aim was to see whether a patent will prove to be profitable or not, whether it would present value in patenting itself. Derwent Innovative makes the most sense as a solution for this set of authors as well given that it is extremely data oriented and very focused on whether or not profitability is a part of the equation. By helping users build a complete picture of what they are working on, it can help mitigate infringement risk, help evaluate competition, and help find intellectual property the value it should have.

There are a number of commercial products on the market for the management of trademarks, patents, and industrial and utility models, but the financial costs of acquiring SW support are in the dozens of thousands of USD for each institution. In addition, it is important to bear in mind that additional maintenance fees are still payable, and none of the products are aimed at an academic environment characterized by a certain specificity. The publication of selected parts of the database to the general public could create an environment for the stock exchange with the results of creative activity and thus increase the success of commercialization.

\subsection{Opinion of Chosen Head of Technology Transfer Offices in the Czech Republic}

Based on the interviews carried out in three monitored areas-description of the process, evaluation of the efficiency of the process, and related cost and potential risks- the findings are described in Table 2.

Furthermore, the interviews suggest custom solutions, business logic, and system requirements are inspired by both existing professional tools and feedback from interventions. The solution itself is promising especially for smaller universities, which, however, in the Czech Republic is considerable and in relation to the amount of applied outputs, a tailor-made solution is sufficient in the temporary state. 
Table 2. Description of main interview results.

\begin{tabular}{cc}
\hline Question Area & Answer Summary \\
\hline In terms of functional requirements and information \\
management, the following key issues should be \\
recorded: \\
research results (originators/authors, date of the result \\
notification, owners, links to related legal protection) \\
legal protection (patents, industrial designs, utility \\
models, owners, producers, date of registration, date \\
of publication, date of granting/registration, brief \\
description, schedule with reminders, legal protection \\
related, persons) \\
For each record to follow its life cycle and from \\
opportunity, through opportunities, partnerships, \\
contracts, documentation, communications, and \\
finance associated with it.
\end{tabular}

Based on interviews, effective tools for technology transfer management need to fulfil some requirements:

- Industrial rights registration/database with search mask

- Database of own industrial rights from their creation to their termination

- Watch deadlines and email notifications

- Monitoring of all-important events with user adjustable advance

- Creation of printed templates (reports and announcements)

- Generating statistics on the activities performed

- Monitoring and planning of costs associated with industrial property protection

In order to achieve the above points, the required software features were analyzed, especially in terms of data structure. Based on this analysis, a basic data model was created. From the basic data model, a so-called class diagram describing relations and inheritance between individual model entities was created, as shown in Figure 1. The central entity in the class diagram is the "protectionCase" entity that represents the intellectual property right (IPR) case itself. This central entity has binding relationships to other model entities that more specifically specify the protection case. These are entities of the inventor, faculty, and entities of the case registration and application of the case. A very important entity is the states and state machine, which implements the business logic of the protection case. 


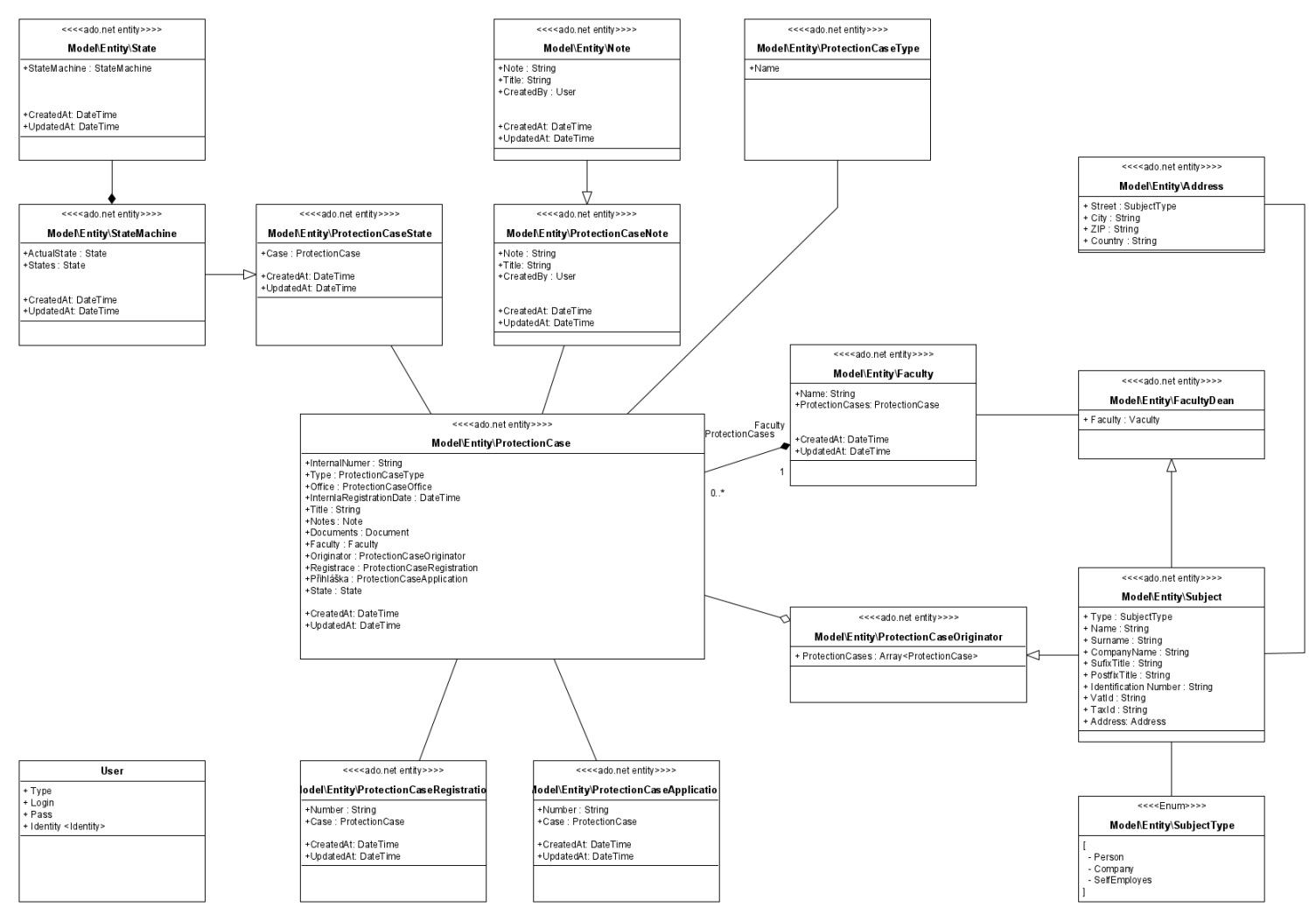

Figure 1. Class diagram of relation and inheritances between model entities. The "protectionCase" is the central entity which represents the intellectual property right (IPR) case itself. The states and state machine implement the business logic of the protection case.

In the class diagram, the entity representing the user is not forgotten either. The role of the user and permissions will be further specified in the next phase of the project.

\subsection{Basic Business Logic and Data Model of Required SW Solution}

In the next step, the business model of the legal protection case was analyzed. For the initial analysis, existing university documents were used for solving cases of IPR. This is an important step for analysis of available suitable SW solutions on the market. The analysis resulted in a state model of the legal protection case. This model describes the individual states of the case and the individual transitions between these states. The state model thus represents the basic business logic of the software. The state model can be also divided into several sub-processes. Within the definition of business logic, the basic competencies were also defined, which in the simplest case are divided between the inventor of the case of legal protection and the department for dealing with the case of legal protection.

Own states are solved by individual processes as shown in Figure 2. The statuses in the "Process-Creation" maps the entry of a new case into the system. Since the protection case itself requires a lot of data and annexes, it would be inconvenient to ask the inventor in a single form. Business logic thus needs to allow the case which is going to be entered into the system even though it does not contain all the necessary information. Subsequently, the inventor can freely add data to the system. When all the conditions for filing a case at the falling office are fulfilled, the case goes into the "Process-Filled" state. Even at this stage, the inventor can still be modified. The inventor has the possibility to refer the case to "Process-Validation", as shown in Figure 3. 


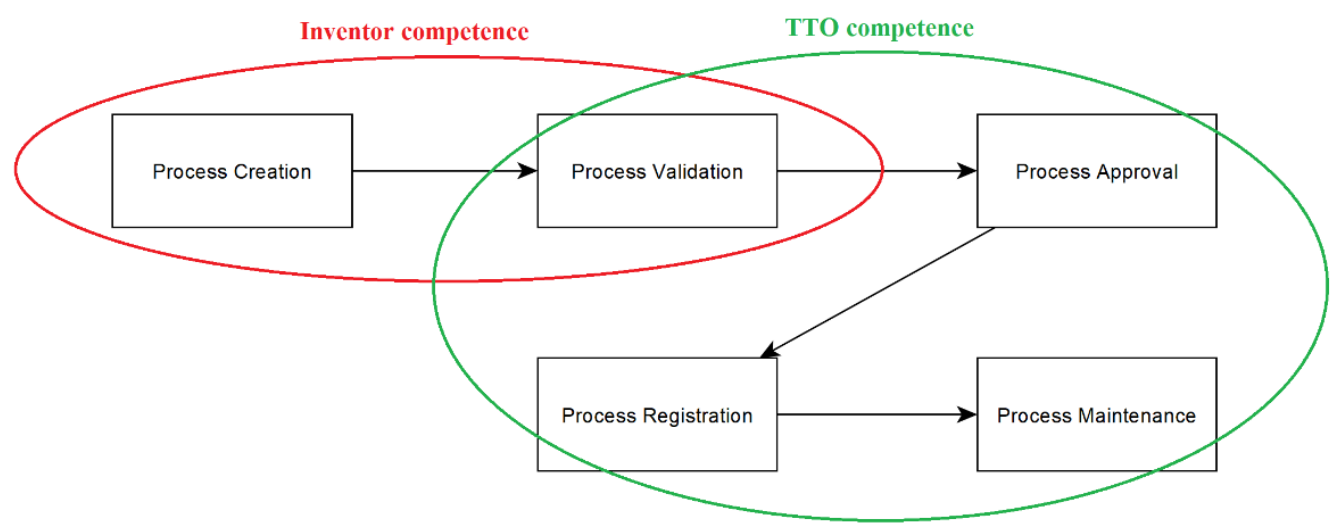

Figure 2. Processes of state model.

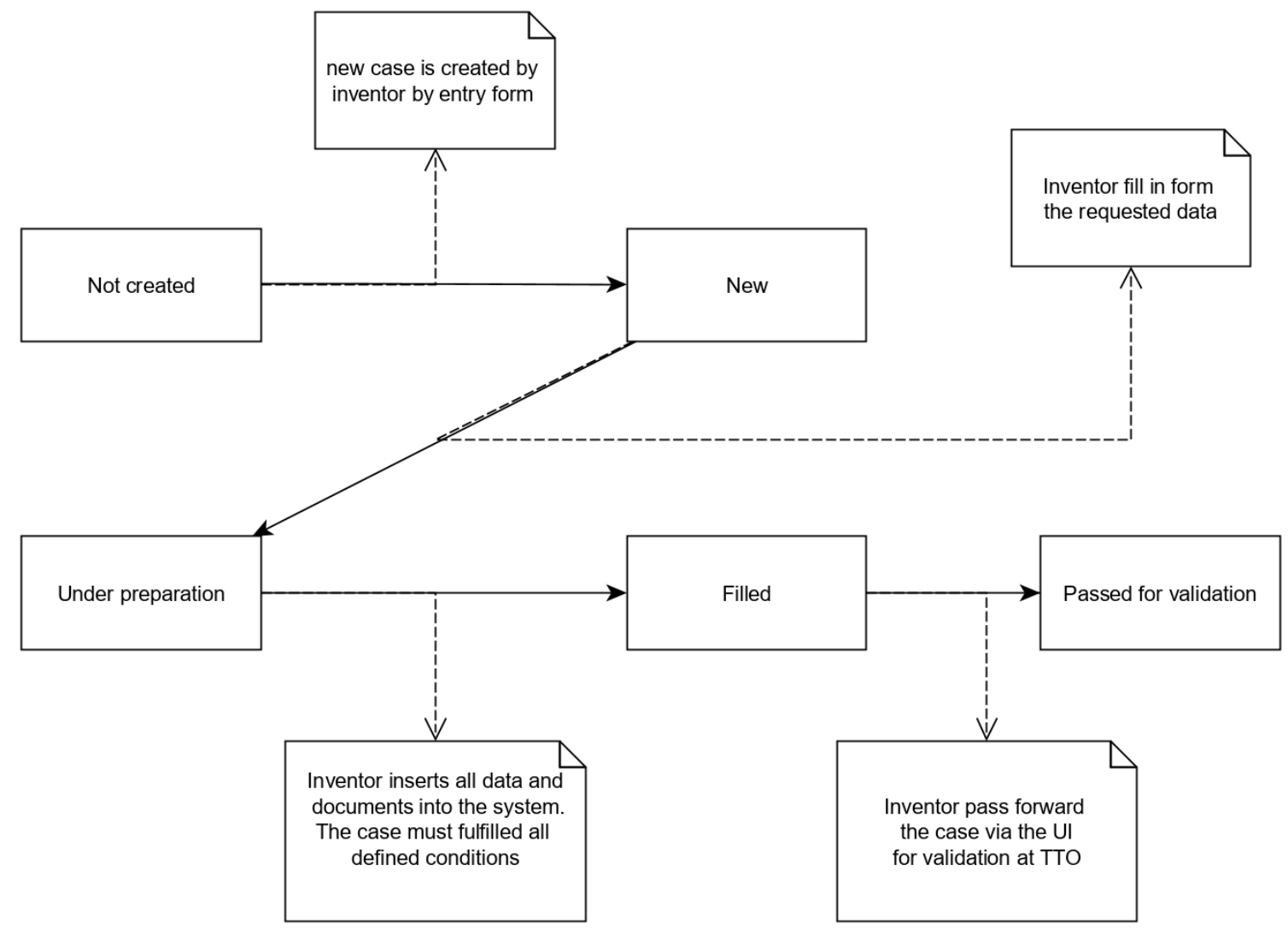

Figure 3. States of process "Process-Creation".

In the validation process, as shown in Figure 4, the states map the procedure for the approval of a legal protection case. First, the authorized officer checks the formal aspects of the cases and the attached documents. The next step is the searching for the similar solutions of the case. In the case that some errors are detected in the filled form, the case may be returned to the inventor for updating. The corrected case returns to the beginning of the validation. After passing the process "Process-Validation", the case needs to be approved by the representative of a responsible faculty. This process maps the passage of approval through the faculty management, which has the opportunity to comment on individual cases and subsequently approve or disapprove. In the last part of business logic, the procedure in the actual submission of the case is mapped to the relevant authorities. The software will generate the appropriate documents needed to file a case with the authority. Subsequently, the procedure of filing is monitored, including the situation when the office returns the case with comments and correction of these comments. All processes, their states, and transition conditions are 
requested to be implemented as data structures in the database as an ideal case. This ensures their variability and the possibility of changing the process. This will ensure high robustness of the system in terms of business logic and the possibility of customization.

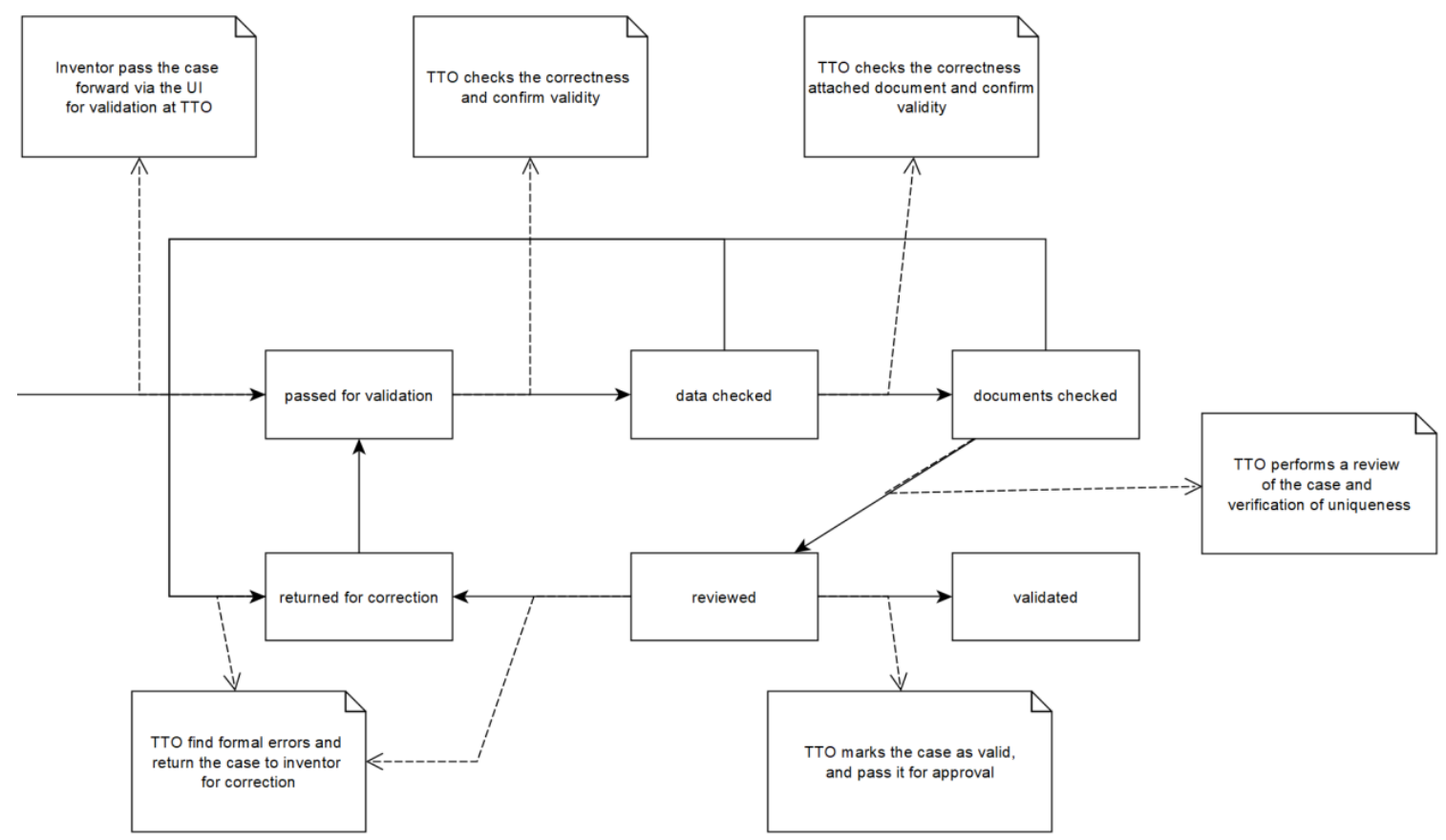

Figure 4. States of process "Process-Validation", which is important to reach the validated form of the IP case to ensure it is clear from all possible mistakes.

Consequently, other processes were evaluated and updated into the state model, which created an exact requests summary. This then needs to be fulfilled by the SW solution, which can be selected from available commercial SW solutions.

\subsection{Strength and Weaknesses of Available SW Solutions-Summary from Literature and Interviews}

In summary, the results of the literature review, SW review, and interviews focused on feedback on the proposed model in the context of current business practice are described in Table 3.

From the above text in Table 3, and based on the defined requirements by university technology transfer offices, it is obvious that the one of the most critical issues which need to be covered by SW solutions is "Deadline management". The second most important issue is docketing management, and also related document storage in a comfortable way. As the university transfer office needs to manage trademarks from university logos and others, this management is also requested. Based on the summary, as shown in Table 1, these conditions are not fulfilled by Acclaim IP from Anaqua, About Innovation, and Symphony from the MaxVal Group. Due to the complexity of tasks of the university TTO, information disclosure also needs to be solved with IP cases. As these are also requirements, we need to also exclude TM Cloud SW solutions. This SW also does not fulfill the feature of "Spend management", which is important for university TTOs, when the remuneration to the inventor of IP is determined based on the university strategy.

The remaining selected SW solutions (Inteum, IPzen Professional, FoundationIP, IDEAS, Thomson IP Manager, and Derwent Innovation) are formally acceptable as potentially suitable. The Inteum SW [32] has great customer support and the ability to create new templates within the inventor portal. A disadvantage is in the supporting of only the Internet Explorer browser, as the preferred one at universities is Google Chrome. Some users also report problems while trying to update older 'legacy' files, which is difficult to impossible, as it creates cryptic error messages. Analytics is not 
very user friendly and the help information is too technical to follow. However, the most problematic is the fact that there are a lot of assumptions made in the design which are not applicable to all institutions, so in the case of university-specific processes, there is a complication on the smoothness of the processing workflow.

Table 3. Evaluation of SW solutions within a qualitative interview.

\begin{tabular}{ccc}
\hline Properties & Strengths & Weaknesses \\
\hline Functionality & $\begin{array}{c}\text { Inteum, FoundationIP, Thomson } \\
\text { IP Manager, Derwent Innovation, } \\
\text { Acclaim IP }\end{array}$ & TM Cloud \\
\hline Reliability & $\begin{array}{c}\text { Inteum, Derwent Innovation, } \\
\text { Acclaim IP }\end{array}$ & \\
\hline Maintenance & Thomson IP Manager & $\begin{array}{c}\text { Inteum, IPzen, Derwent } \\
\text { Innovation }\end{array}$ \\
\hline User experience & Acclaim IP, TM Cloud, About & IPzen, Inteum, FoundationIP, \\
& Innovation & Acclaim IP \\
Deadline management & Inteum, IPzen Professional, \\
& $\begin{array}{c}\text { FoundationIP, IDEAS, Thomson IP } \\
\text { Manager, and Derwent Innovation }\end{array}$ & Inteum, IPzen Professional, \\
Docketing management & $\begin{array}{c}\text { FoundationIP, IDEAS, Thomson IP } \\
\text { Manager, and Derwent Innovation }\end{array}$ & Acclaim IP, About Innovation \\
\hline Trademarks & $\begin{array}{c}\text { Inteum, IPzen Professional, } \\
\text { FoundationIP, IDEAS, Thomson IP } \\
\text { Manager, and Derwent Innovation }\end{array}$ & $\begin{array}{c}\text { Acclaim IP, About Innovation, and } \\
\text { Symphony }\end{array}$ \\
\hline
\end{tabular}

The second possible solution is IPzen [33] which can be accessed easily from anywhere as it is very simple to get while on the road. The problem is at the level of required user knowledge, as this software is not easy to learn. It took a lot of time of trialing to try and integrate each person, on every level, to this system.

FoundationIP [36] has the ability to create complex reports that are very useful in university TTO practice and speed up the preparation process for every meeting with potential industry partners/customers. However, the user needs to be an advanced user to find it a powerful tool. Foundation IP is not at all intuitive. Even after a year of use and some training, it is still difficult to use. It takes a huge amount of time in figuring out how to navigate the system. Non-trained users, such as the potential inventors to the university academics will not be able to use it, which is very problematic. There are also many cases regarding frequent crashing, and it takes a long time to load between screens.

For the Thomson IP Manager [39], mainly docketing and asset management features are the advantage, as well as its remote accessibility, which is good for users who travel a lot, like academics do frequently. The problem is again the incompatibility of processes with university flow, where the processes of the SW are preprogramed so it is not possible to use this feature. Furthermore, this solution contains many more features than the university TTO needs, so the price is relatively high for the required defined needs.

The last possible and suitable SW solution is Derwent Innovation [40], which allows for a more confident set of decisions when it comes to IP, because of the use of scientific literature, global patent data, and business data-all of which are linked to strong analytics and easy workflow tools. It is a very powerful and complex solution, which is the best one, only with one issue, which is the extremely high price, which is impossible to use even at a mid-size university TTO.

Last but not least, the criteria for selection of a suitable SW solution is the price of the solution for the company or the university. Company and university TTO needs are based on the purpose of the TTO office in such a specific institution. A company can support this TTO by significantly more money, 
as IP is one of the most valued properties of the company; thus, the importance of SW solutions for IP management is very high. The university case is different because the purpose of the university is not only technology transfer, but also knowledge transfer and advertisement of any ability for society and companies. The final decision on selection of SW solutions is thus very affected by the financial budget. Not rarely, the use of proprietary solutions, such as Microsoft (MS) Dynamics or even MS Excel, are used instead of the special SW solutions discussed above in this article. This fact is given by the real amount of IP cases in a university TTO, where only several real cases per year are conducted. For this specific aspect, we can conclude with a suggestion of Acclaim IP from Anaqua and FoundationIP for a university TTO as a good option for good money, even if they do not meet every criterion, such as trademark or docketing, like for the Acclaim IP case. Foundation IP is a G2 web site used by $42 \%$ of companies which responded to the review. On the other hand, the Inteum SW solution is the same site used by higher education institutions at $46 \%$ worldwide.

\subsection{SW Solutions in the Context of Open Innovation in Intellectual Property Management}

Much scientific literature expresses the topic of open innovation [42]. Universities play a key role as a knowledge base supplier [43]. In many cases, it is possible to see how actively universities use and fulfill this role [44]. For universities, the notion of open innovation is more critical than for others in the context of technology transfer. Open innovation was defined as "the use of purposive inflows and outflows of knowledge to accelerate internal innovation, and expand the markets for external use of innovation, respectively" [6]. Once the concept of open innovation is accepted, it is possible to combine internal resources with external entities and their know-how and equipment. This is also the aim of a TTO; to link the emerging know-how with the external environment, to ensure the applicability of the results, and to meet the demand coming from the external environment. From the perspective of companies, this interconnection of the university is described by Gassmann and Enkel [45], who distinguish between three forms of cooperation. The first is "Outside-In", which means that external knowledge is used for internal innovation and results in new products as required by the external environment. Furthermore, "Inside-Out", where their own knowledge and their interconnection will result in innovation. The last is the term "linked process", which is used to characterize innovative networks. In this case, the two previous strategies "Outside-In" and "Inside-Out" are actually interconnected to meet market demand and requirements [45]. Consequently, a distinction must be made between the places of knowledge creation, technological implementation, and market commercialization [43]. According to Perkmann, Tartari, McKelvey, et al., academic engagement can be defined as "knowledge-based collaboration by academic scientists with non-academic organizations" [46]. This interaction includes formal activities, such as collaborative research, contractual research, and consultation, as well as informal activities such as ad hoc counseling and networking. In fact, this channel also includes human interactions.

With a knowledge management model being in place, some issues, such as provision of administrative support associated with the protection of the intellectual property itself, as well as securing links with experts and leaders in the field for possible follow-up research and development; a well-functioning team working under transparent internal rules in a supportive and motivating environment, which is related to adequate workplace equipment to create a good place for work; a good knowledge of internal processes for handling results with intangible assets, and a clearly defined notice of an achieved R\&D result that needs to be addressed in terms of intellectual property protection; addressing suitable business partners interested in applying the protected research result in practice, communicating with business partners and facilitating a contractual relationship, or other form of possible subsequent cooperation; and collaborating with other scientific teams (internal, national, and international), will be addressed. From the point of view of the protection of intellectual property are then the process of recording things, like the joint patent application, points out that there is cooperation within innovation, which can be described as a form of open innovation [47]. Co-ownership of patents can mean their high quality and the consequent positive impact on the entity's performance and market 
position [48]. Co-ownership of intellectual property explores the consequences of appropriation of values and the creation of co-patenting values with different partners [49]. Shared rights to a patent or other form of intellectual property protection usually occur as a result of cooperation and can therefore be considered as a special result of cooperation, again as a form of open innovation [50].

In all these cases of cooperation, describing knowledge flows from the university to the application sphere, it must be possible to capture the process and capture the follow-up steps associated with commercialization, effectively recording them so that stakeholders have maximum administrative support. All the energy generated is directed towards effective knowledge management. Thus, the authors consider it essential that TTOs have an appropriate SW solution available to capture the context.

\section{Conclusions}

The world is fast moving towards transforming itself into a knowledge economy. Be it the developed world or the developing world, the importance of protecting intellectual property has never been as pronounced as it is now. As the world moves ahead in this environment, more and more of our actions are being informed and molded by how knowledge can be commercialized and can create profit.

Knowledge-based assets, such as intellectual property or patents, provide a competitive edge to companies and individuals. It makes sense to not only continue to innovate because of the needs of the knowledge economy, but to also constantly think about how these innovations can help create profit. All these lead to a serious need for a system that can help manage intellectual property.

The solutions that this review outlined are technology based. We looked at software that can handle the task and found that a number of viable options were SaaS or cloud based, meaning they could be connected remotely and offer global solutions. In this day and age where brands are now competing in multiple countries, it is imperative that an IP management system be one that can operate on a global scale as and when required. Suitability to requirements defined by university TTOs was discussed, where we found that no one is the winner. Every solution has some limitations for specifically defined requirements, namely, where the limited budget is preferred and conformity with specific processes at the university level of the existing IP process. As a result of this study, we are suggesting that university TTO managers responsible for TT need to define a specific balance between several parameters to find the best SW solution for IP management for their university case. Here we are pointing out these parameters as a result of our study, from the most important for the studied cases down to the least important:

- Value of the SW solution and limit of the budget they hold;

- $\quad$ Fulfilment of mandatory activities and responsibilities of TTO managers based on the process analysis (as in Section 4);

- $\quad$ Representation of university know-how for companies, customers, society (reporting);

- $\quad$ Possibility to update SW solutions to specific university needs.

However, the limitations of these findings are the limitations of the literary research, its scope, the search on the websites of private companies, and the limited number of interview respondents. At the same time, the aim of the paper was not to comprehensively describe the current best solution in the dynamically developing area of IT. The main goal was to point out the key facts that should be reflected in the selection of the relevant SW in relation to the offices of the technology transfer universities.

Author Contributions: O.K., P.M., A.S., and K.K. suggested the design of the study and wrote the methodology, and supervised the whole research; P.M. and O.K. searched the databases and prepared the tables; R.H., O.K., R.F., P.M., and A.S. contributed to interpretation of data and validation of results, and visualization; O.K., P.M., and R.H. drafted the manuscript; P.M., O.K., R.F., A.S., and K.K. reviewed and revised the paper according to reviewers' comments; O.K., P.M., A.S., and K.K. contributed to project administration and funding acquisition. All authors approved this version of the paper. All authors have read and agreed to the published version of the manuscript.

Funding: This work was supported in part by the project TACR ETA 2 with No. TL02000066 "Effective knowledge transfer management", and by SPEV project 2103 at University of Hradec Kralove, FIM, Czech Republic (2020). 
Acknowledgments: This publication is based upon work from the project TACR ETA 2 with No. TL02000066 "Effective knowledge transfer management", and by SPEV project 2103 at University of Hradec Kralove, FIM, Czech Republic (2020). We would like to extend our gratitude towards Pavla Matulova and Jan Hruska for their consultation on the research.

Conflicts of Interest: The authors declare no conflict of interest.

\section{References}

1. Arenas, J.J.; González, D. Technology Transfer Models and Elements in the University-Industry Collaboration. Adm. Sci. 2018, 8, 19. [CrossRef]

2. Maresova, P.; Stemberkova, R.; Fadeyi, O. Models, Processes, and Roles of Universities in Technology Transfer Management: A Systematic Review. Adm. Sci. 2019, 9, 67. [CrossRef]

3. Li, F.; Zhang, S.; Jin, Y. Sustainability of University Technology Transfer: Mediating Effect of Inventor's Technology Service. Sustainability 2018, 10, 2085. [CrossRef]

4. Choi, J.; Jang, D.; Jun, S.; Park, S. A Predictive Model of Technology Transfer Using Patent Analysis. Sustainability 2015, 7, 16175-16195. [CrossRef]

5. Chen, J.; Zhao, X.; Wang, Y. A new measurement of intellectual capital and its impact on innovation performance in an open innovation paradigm. Int. J. Technol. Manag. 2015, 67, 1-25. [CrossRef]

6. Chesbrough, H.; Crowther, A.K. Beyond high tech: Early adopters of open innovation in other industries. R D Manag. 2006, 36, 229-236. [CrossRef]

7. Siegel, D.S.; Veugelers, R.; Wright, M. Technology transfer offices and commercialization of university intellectual property: Performance and policy implications. Oxf. Rev. Econ. Policy 2007, 23, 640-660. [CrossRef]

8. Siegel, D.S.; Wright, M. Intellectual property: The assessment. Oxf. Rev. Econ. Policy 2007, 23, 529-540. [CrossRef]

9. Caldera, A.; Debande, O. Performance of Spanish universities in technology transfer: An empirical analysis. Res. Policy 2010, 39, 1160-1173. [CrossRef]

10. Squicciarini, M. Science Parks' tenants versus out-of-Park firms: Who innovates more? A duration model. J. Technol. Transf. 2008, 33, 45-71. [CrossRef]

11. Wright, M.; Liu, X.; Buck, T.; Filatotchev, I. Returnee entrepreneurs, science park location choice and performance: An analysis of high-technology SMEs in China. Entrep. Theory Pract. 2008, 32, 131-155. [CrossRef]

12. Markman, G.D.; Phan, P.H.; Balkin, D.B.; Gianiodis, P.T. Entrepreneurship and university-based technology transfer. J. Bus. Ventur. 2005, 20, 241-263. [CrossRef]

13. Siegel, D.S.; Phan, P.H. Analyzing the Effectiveness of University Technology Transfer: Implications for Entrepreneurship Education. Adv. Study Entrep. Innov. Econ. Growth 2005, 16. [CrossRef]

14. Graff, G.; Heiman, A.; Zilberman, D. University research and offices of technology transfer. Calif. Manag. Rev. 2002, 45, 88-115. [CrossRef]

15. Schoen, A.; van Pottelsberghe de la Potterie, B.; Henkel, J. Governance typology of universities' technology transfer processes. J. Technol. Transf. 2014, 39, 435-453. [CrossRef]

16. Ismail, K.; Omar, W.Z.W.; Majid, I.A. The commercialisation process of patents by universities. Afr. J. Bus. Manag. 2011, 5, 7198-7208.

17. Liu, T.-W.; Chin, K.-S. Development of audit system for intellectual property management excellence. Expert Syst. Appl. 2010, 37, 4504-4518. [CrossRef]

18. Aldieri, L.; Kotsemir, M.; Vinci, C.P. The impact of research collaboration on academic performance: An empirical analysis for some European countries. Socio-Econ. Plan. Sci. 2018, 62, 13-30. [CrossRef]

19. Adams, W.C.T. Conducting Semi-Structured Interviews; Jossey-Bass: San Francisco, CA, USA, 2015.

20. Porrawatpreyakorn, N.; Quirchmayr, G.; Chutimaskul, W. Requirements for a Knowledge Transfer Framework in the Field of Software Development Process Management for Executive Information Systems in the Telecommunications Industry. In Advances in Information Technology; Papasratorn, B., Chutimaskul, W., Porkaew, K., Vanijja, V., Eds.; Springer: Berlin, Germany, 2009; pp. 110-122. 
21. Barac, M.; Kukolj, S.; Antin, M.; Kukolj, D. Software support of the process of managing intellectual property. In Proceedings of the 2015 23rd Telecommunications Forum Telfor ( ${ }^{\mathrm{TEL}}$ FOR), Belgrade, Serbia, 24-26 November 2015; pp. 866-869.

22. Gargate, G.; Momaya, K.S. Intellectual property management system: Develop and self-assess using IPM model. World Pat. Inf. 2018, 52, 29-41. [CrossRef]

23. Tsybulskaia, L.A.; Ryabtseva, E.E.; Strashko, E.V.; Zelinskhaya, E.L.; Elistratova, A.L. Management System Concept for Commercialization of Intellectual Property Objects Regarding Interest Alignment. In European Proceedings of Social and Behavioural Sciences; Future Academy: Nicosia, Cyprus, 2019; pp. 1211-1219.

24. Charavay, C.; Segard, S.; Pochon, N.; Nussaume, L.; Javot, H. SeedUSoon: A New Software Program to Improve Seed Stock Management and Plant Line Exchanges between Research Laboratories. Front. Plant Sci. 2017, 8, 13. [CrossRef]

25. Yu, X. University intellectual property management system design and functional study. Agro Food Ind. Hi-Tech 2017, 28, 48-51.

26. Kadir, K. Intellectual Property Rights (IPR) Management and Monitoring Framework for University Innovation Centre; Center for Artificial Intelligence Technology: Langkawi, Malaysia, 2018; Available online: https://www.semanticscholar.org/paper/Intellectual-Property-Rights-(-IPR-)-Management-andKadir-Salim/60c6d0ec94900ad7c6c18a0d32c450d29558b63f (accessed on 29 March 2020).

27. Dirnberger, D. The use of mindmapping software for patent search and management. World Pat. Inf. 2016, 47, 12-20. [CrossRef]

28. Xiaohui, T.; Yaohui, Z.; Yi, Z. The Management System of Enterprises' Intellectual Property Rights: A Case Study from China. IJABIM 2012, 3, 50-64. [CrossRef]

29. Wang, W.M.; Cheung, C.F. A Semantic-based Intellectual Property Management System (SIPMS) for supporting patent analysis. Eng. Appl. Artif. Intell. 2011, 24, 1510-1520. [CrossRef]

30. Trademark Patent IP Docketing Software-TM Cloud. Available online: https://www.tmcloud.com/?utm source $=$ capterra (accessed on 3 January 2020).

31. United States Patent and Trademark Office. Available online: https://www.uspto.gov/ (accessed on 3 January 2020).

32. Intellectual Property Management Software Inteum Company LLC. Available online: https://www.inteum. com/ (accessed on 4 January 2020).

33. IPzen: Case Management Solution in a Cloud (Trademarks, Domain Names). Available online: https: //www.ipzen.com/ (accessed on 3 January 2020).

34. About Innovation/Reinventing IP Portfolio Management. Available online: https://www.aboutinnovation. com/ (accessed on 4 January 2020).

35. CPA Global. IP Management Software/Foundation IP. Available online: https://www.cpaglobal.com/en-us/ ip-management-software/foundationip (accessed on 4 January 2020).

36. IDEAS. IDEAS—Intellectual Property (IP) Management. Available online: http://ideas.barcelona/ (accessed on 27 March 2020).

37. IP Management Software/IP Portfolio Management/MaxVal. Available online: https:/www.maxval.com/ symphony.html (accessed on 4 January 2020).

38. Anaqua Anaqua IP Management Software and Services. Available online: https://www.anaqua.com/anaquaip-management-software-and-services (accessed on 4 January 2020).

39. Clarivate Analytics. 2017 Clarivate Analytics Releases Thomson IP Manager 4.5; Clarivate Analytics: Philadelphia, PA, USA, 2017.

40. Derwent Innovation. Available online: https://clarivate.com/derwent/ (accessed on 27 March 2020).

41. Kadir, K.; Salim, J. Intellectual property (Ip) management and monitoring prototype system for university innovation centre. J. Theor. Appl. Inf. Technol. 2016, 84, 31-41.

42. Yun, J.J.; Zhao, X.; Wu, J.; Yi, J.C.; Park, K.; Jung, W. Business Model, Open Innovation, and Sustainability in Car Sharing Industry-Comparing Three Economies. Sustainability 2020, 12, 1883. [CrossRef]

43. Becker, B.A.; Eube, C. Open innovation concept: Integrating universities and business in digital age. J. Open Innov. 2018, 4, 12. [CrossRef]

44. Yun, J.J.; Liu, Z. Micro- and Macro-Dynamics of Open Innovation with a Quadruple-Helix Model. Sustainability 2019, 11, 3301. [CrossRef]

45. Gassmann, O.; Enkel, E. Towards a Theory of Open Innovation: Three Core Process Archetypes; University of St. Gallen: St. Gallen, Sweden, 2004. 
46. Perkmann, M.; Tartari, V.; McKelvey, M.; Autio, E.; Broström, A.; D’Este, P.; Fini, R.; Geuna, A.; Grimaldi, R.; Hughes, A.; et al. Academic engagement and commercialisation: A review of the literature on university-industry relations. Res. Policy 2013, 42, 423-442. [CrossRef]

47. Ma, Z.; Lee, Y. Patent application and technological collaboration in inventive activities: $1980-2005$. Technovation 2008, 6, 379-390. [CrossRef]

48. Briggs, K. Co-owner relationships conducive to high quality joint patents. Res. Policy 2015, 44, $1566-1573$. [CrossRef]

49. Belderbos, R.; Cassiman, B.; Faems, D.; Leten, B.; Van Looy, B. Co-ownership of intellectual property: Exploring the value-appropriation and value-creation implications of co-patenting with different partners. Res. Policy 2014, 43, 841-852. [CrossRef]

50. Yun, J.J.; Jeong, E.; Zhao, X.; Hahm, S.D.; Kim, K. Collective Intelligence: An Emerging World in Open Innovation. Sustainability 2019, 11, 4495. [CrossRef]

(C) 2020 by the authors. Licensee MDPI, Basel, Switzerland. This article is an open access article distributed under the terms and conditions of the Creative Commons Attribution (CC BY) license (http://creativecommons.org/licenses/by/4.0/). 